\title{
Tattoos as Narratives: Skin and Self
}

\author{
Chris William Martin ${ }^{1}$, \\ Memorial University, \\ Newfoundland, Canada
}

\begin{abstract}
This article explores the polysemic nature of contemporary tattoos by comparing interviewees' perceptions of the meanings of their tattoos with the meanings which can be imputed to them by a researcher studying cultural history and semiotics. After systematically comparing the referencing and mapping of tattoos by interviewees in St. John's, Newfoundland, the author argues that tattoos should be viewed in a light that reflects the endless potential of human self-expression. Part of this statement is meant to address the structure-agency dichotomy which has long been reflected in the literature on sociological theories and the tattooing/body literature. Another part is meant to give substantive evidence to the claim that regardless of motivations or meanings, the truth behind meaning and identity can only be found in complex and ephemeral moments which populate the life of the cultural and individual actor.
\end{abstract}

\section{Introduction}

Against the backdrop of our late-modern world tattoos are becoming more complex symbols of our self and social identities. Because of the growing complexity of the modern tattoo, this research proposes that these ink marks need to be viewed with the same symbolic complexity that reflects their contemporary artistic designs. In the following discussion I focus on the tattoos which people don so that we may explore their deep meaning; and so we may appreciate tattoos as semiotic representations of the individual and culture it effects and is affected by. I will argue these points through the visual aid of my interviewees' art works, their own understanding of the meanings of their tattoos, and ideas about the meanings of symbols from history and semiotics. I organize this information around concepts Stephen Harold Riggins $(1990,1994)$ introduced in material culture studies, referencing and mapping. We demonstrate cultural sophistication when we "reference" objects by talking about their

\footnotetext{
1 cwmartin@mun.ca
} 
aesthetics, history or customary use. When we use objects as a way of talking about people and personal experiences, we "map" objects. Conversations about domestic artifacts (for example, objects displayed in living rooms) consist primarily of mapping. I try to see if the same is true for tattoos. The fact that tattoos are more personal than domestic artifacts may result in even more talk classified as mapping. Referencing and mapping delineate multiple meanings as they fall in line with cultural/historical connections, on one hand; and personal/familial relations on the other. Perhaps the most original aspect of this discussion is the detailed biographical and aesthetic information I have gathered from my interviewees about their tattoos. Although this might seem an obvious topic to explore, it has rarely been done by sociologists studying tattoos.

This article is organized so that readers first learn to appreciate the tattoo literature. This is followed by a section which depicts the methodology used in this study. Then I provide an in-depth and original analysis of six of my research participants' tattoos. In this analysis section, readers will be introduced to three categories of tattoo enthusiasts which allow for new understandings of the complexities tattoos can hold. These three categories of individuals who I have called the Social Peacocks, Familial Hearts, and Beauty and Art enthusiasts are not meant to represent all of the tattooed population. Instead they allow for an understanding of some of the motivations, meanings, and connections to identity that tattoos have. They also allow for an exploration of the concepts of referencing and mapping as they help to apply Anthony Giddens' structuration theory in recognizing the social action of becoming tattooed as one that is complicated by both individual and cultural factors.

\section{Giddens' Structuration Theory}

Anthony Giddens (1991: 75-77) writes in Modernity and Self-identity that "the self is seen as a reflexive project, for which the individual is responsible. We are, not what we are, but what we made ourselves.... The reflexivity of the self extends to the body, where the body is part of an action system rather than merely a passive object." I believe the principles that Giddens describes as characterizing "high" or "late" modernity explain what it means to be human today, and importantly, how our bodies are connected to the ongoing process of actualizing a self-identity. The principles of constant reproduction of self in social interaction, the influence of conscious individual intent (or agency) as well as enabling and constraining structures, and the search for ontological security are all reflected in this article. 
Giddens' structuration theory is of paramount importance to this discussion and to the understanding of the process of becoming tattooed and the meanings and motivations behind the marks. Whether studying the tattoo as artistic expression, body project, commodity, or vehicle for the self, some strikingly similar debates enter into the literature. I refer to those debates which attempt to pinpoint body alterations as a result of structures of influence or expressions of individual control (e.g., Shilling 1993; Foucault 1977, 1982; Sanders 1989, etc.). Giddens' structuration theory is unique because it offers divergent nodes of thought from these dichotomous loops. Allowing for an understanding of the potential for structure and agency to be in a symbiotic rather than dichotomous relationship, Giddens argues, is most productive to the pursuit of knowledge about cultural acts. This is primarily because cultural acts which involve the conscious action of an agent, as well as the systems of knowledge and practice which come to be socially created and signified, have all been processed in tandem rather than separately from each other. In Giddens' (1985: 25) words: "analyzing the structuration of social systems means studying the modes in which such systems, grounded in the knowledgeable activities of situated actors who draw upon rules and resources in the diversity of action contexts, are produced and reproduced in interaction.” This quotation allows for a useful summation of the ingredients in understanding structuration theory and further, to understanding all social/cultural acts. Acknowledging the role of knowledgeable actors as well as the importance of social systems/structures in making up the components of the social construction of reality is of key importance to understanding how it is that an act like indelibly marking the skin with ink must always be understood as both an individual and cultural affair. If we understand this to be the case, we must also realize how meaning and identity attributed to a social act like becoming tattooed will also have deep and varied interpretations and systems of significance.

\section{How Did We Get Here and Where Are We Going: A Brief History of Western Tattoo Practices and the Sociological Literature on Tattooing}

The historically rich origins of tattooing in North America - which is no more creative than the designs indelibly marked on the surface of bodies everywhere - is said to have begun with the English exploration vessel The Endeavor and its Captain, James Cook (Sanders 1989; Pitts 2003; Atkinson 2003). Ten years after Cook and his crew finished plotting out the new British territory known as Newfoundland in 1759, they were sent to the South Pacific for 
further exploration. It is in the South Pacific that the tatau (a Tahitian word, meaning "to strike") was observed, recorded, and eventually exported back to Europe. Now known as a "tattoo," the practice travelled back on the arms of many sailors, as well as in the form of a living Tahitian prince named Omai. The practice has since been regarded in many different lights, and according to Michael Atkinson, has seen a "sociogenesis" (2003) ranging from associations with different social classes, as well as varying in the degree of consideration as deviant status. According to Atkinson (2003: 24, 30-50), "tattoos are best understood within generational moments" and can be divided into six distinct eras which reflect the differing fields of cultural production. These eras are the colonist/pioneer, circus/carnival, workingclass, rebel, new age, and finally supermarket era(s).

As Clinton Sanders points out in his text Customizing the Body: The Art and Culture of Tattooing, the journey from craft to art, or outlawed deviant activity to partially-respected social outlet, was long and quite difficult. Sanders $(1989: 3,21)$ appropriately notes in his introduction that: "those who define tattooing as an artistic practice are deeply involved with a process of collective legitimation" and later, that "body alteration is culture; it is meaningful to the members of the society in which it occurs, and it is produced within complex webs of collective action." Sanders backs the claim of the meaningfulness of tattooing by stating that "tattooing is being moved away from its roots as a widely devalued craft-like practice pursued by producers and consumers who are marginal to mainstream social groups. In turn, impelled by the purposive activities of a variety of committed individuals, it is coming to be defined as an art form..." (Sanders 1989: 21). Throughout Sanders' text on the world of tattooing, he remains adamant about the fact that tattooing is important for social communication, for holding meaning, and as a cultural signifier.

While differentiating between "types" of tattooists and their reasons for interest in the occupation Sanders quotes a "fine art" tattooist who is (as is typical for this type of tattooed individual) in search of an "art form that offered a creative outlet." The respondent remarks "the first female I ever saw with a tattoo was a friend of mine ... the whole image of it looked like a piece of art work instead of the idea we usually project onto a tattoo" (Sanders 1989: 67). While exploring what it means to "become a tattooed person," Sanders, through use of Goffmanian concepts, aptly notes that "the tattoo becomes an item in the tattooee's personal “identity-kit." However varying and quite personal the reasons for getting tattoos or becoming a tattooist may be, Sanders' final message that despite these deep lines of meaning which may permeate the inked skin, the tattoo remains (and will remain) - explicitly - a deviant activity, still existing on the fringes of culture but segregated to a subcultural status. 
Heavily influenced by the theory of figuration introduced by Norbert Elias, Michael Atkinson carefully and empirically explores tattooing within historical contexts as it shifts through space and time. Notably, while making reference to past theories and avenues of thought concerning tattooing, Atkinson (2003: 23) claims that "the limited sociological analyses of tattooing have viewed the practice from a narrow viewpoint." He also makes reference to what he calls a "cultural stereotype (that) has long held tattoos as marks of shame worn by outlaws, misfits, or those fallen from social grace." What sets Atkinson apart from other academics or social scientists studying the art of tattooing (despite the fact that he is heavily tattooed) is his concept of the practice "as a powerful form of human expression" that need not be outcast as deviant, especially by contemporary standards. For Atkinson (2003: 24), "tattoos are now considerably more open to interpretation and subject to situated definition." Indeed, despite the potential for historical reductionism, one can still make the argument that some of the most valuable sociological contributions to the understanding of cultural and social phenomena are the result of a deep historical and contextual analysis of cultural practices or trends (Foucault 1978, 1982, 1984, 1986; Durkheim 1897, 1912) because it places action within specific social contexts and avoids generality.

As Atkinson argues, noting feminist scholars studying gender and identity politics is a very useful tool of inquiry. One can certainly appreciate the vested interest such intellectuals have in exploring implications of the practice of body modification in terms of gender and oppressive roles. Atkinson (2003: 15-16) notes how theories in this sense have viewed body modification practices from two polar and equally influential stances: "either the ongoing maintenance of hegemonic ideology about femininity or the conscious attempt to subvert patriarchal ideology through bodily resistance." Many have argued that bodies are an integral center point where the powers of society display their influence (Foucault 1977, 1978), but ultimately Atkinson seems to favor defining bodies as a tool for forming "an empowered self" or as a potential "vehicle of liberation."

Importantly, Atkinson (2003: 56- 60) provides a useful summary of three popular categories of sociological analysis of tattooing in the past. These modes of study focus on "tattooing as social deviance; (as an) analysis of tattoo artists and their everyday experience in the business; and investigations of the tattoo as a form of political resistance." Within each of these categories, we find cultural ethnographers digging deep into the practice of tattooing to look at the practice in a myriad of ways, sometimes richly employing forms of looking into the "polysemic nature of cultural understandings" (60; see Mifflin 1997). Other times they look at biopolitical resistance such as how enthusiasts attack outside control over their body, 
for example from the church, through the "urban primitive use of tattooing in Canada (which) is directly opposed to Christian-based codes of bodily display that are part of the hegemony of Western cultures" (Atkinson 2003: 46).

It must be noted that this article builds on the work of Atkinson and others but it also benefits from the current cultural climate of the practice of marking the flesh which is more popular than ever before. Whereas the focus in past theories and avenues of thought was inspired by the current state of the practice and the cultures or fields of cultural production at the time. This discussion falls in this same category but benefits from being part of a culture of tattooing that has never existed quite like it does now. However, this does not discount the stock of knowledge that is still relevant and useful from these inquires. For example, Sanders (1989) concludes that tattoos are in fact deviant or marks of (partial) marginality because of the era in which he completed his influential study. As Atkinson (57) notes, " he was one of the first sociologists to hold firm to the idea that tattooing is a practice subject to social constructions and definitions (deviant or otherwise), and influenced by the personal biographies of, collective world views held by, and contextual interpretations of individuals."

In his text Body and Social Theory Chris Shilling introduces an influential concept and theoretical question called "the body-project." This concept may best be understood by looking at Shilling's definition which states that the "body is most profitably conceptualized as an unfinished biological and social phenomenon which is transformed, within certain limits, as a result of its entry into, and participation in, society. It is this biological and social quality that makes the body at once such an obvious, and yet elusive phenomenon" (Shilling 1993: 11). The body as a project is also meant to be reflective of the idea that in Western societies there is an obsession with changing and altering the body in the search for idealized beauty or perfection. Who is ultimately in control of crafting and evaluating the project is a major question that arises in texts related to the body project.

As the discussion progresses in Shilling's text, advocates on both sides of the debate are represented. For an example of those who attribute the body project to individual agency, Shilling himself argues that through a micro-relationship lens these projects can work in forming one's own self-identity or purposefully displaying this to others through the Presentation of Self in Everyday Life (Shilling 1993: 72; Goffman 1959). From a feminist perspective, author Victoria Pitts notes how "some women have described their body art as a way to rebel against male dominance and to 'reclaim' power over their own bodies. In creating scarred, branded, pierced, and heavily tattooed bodies, they aim to reject the pressures of beauty norms and roles of 'proper' femininity" (Pitts 2003: 3). 
Expanding upon Shilling's body project, Atkinson notes (2003: 25), “body projects intended to camouflage the body (like plastic surgery or make-up) are seen or read by others as an everyday method of presenting favorable images of the self, and typically conform to cultural codes about bodies and norms governing personal representation as a means of communicating a person's commitment to cultural body habits." Atkinson's transformation of the concept in relation to the practice of tattooing presents the idea that although Shilling often favors viewing the body project in a light which helps researchers understand how individual agency can contribute to self-identity, it is also of equal importance to be aware of the other brand of thinkers who will staunchly argue that these kinds of body modifications are actually doomed by the plight of aging, the inevitable breakdown of the body through life's natural course, and the insatiable thirst for obtaining more physical capital by meeting beauty standards of class (see the discussion of Bourdieu in Shilling 1993: 113; Turner 1984). The idea of the never-ending chance of salvation from competitive and oppressive cultural norms is made perfectly evident with a quotation from Durkheim representing Giddens' orthodox consensus of classical sociological theories. While discussing the plight of anomic suicide, Durkheim poetically notes:

Irrespective of any external regulatory force, our capacity for feeling is in itself an insatiable and bottomless abyss. But if nothing external can restrain this capacity, it can only be a source of torment to itself. Unlimited desires are insatiable by definition and insatiability is rightly considered a sign of morbidity. Being unlimited, they constantly and infinitely surpass the means at their command; they cannot be quenched. Inextinguishable thirst is constantly renewed torture (Durkheim 1897: 247).

\section{Reflections on the Literature}

The literature examined above is some of the most influential texts in the sociological analysis of tattooing. It is my intent now to demonstrate how my research, although inspired and indebted by these studies, differs from these texts. First, while each author ambitiously sets his or her sights on analyzing the practice and field of tattooing, I focus instead more specifically on the meanings of the tattoos themselves. Second, in the literature presented it should be noted that readers will be taken on a trip back and forth, between what is considered as the primary ontological understanding for committing an action. Each time the author is attempting to commit the readers' sociological imagination to the idea that it is more a result 
of structures of control, or the power of individual agency, which is responsible for the crafting of ourselves and our bodies in the late-modern world. ${ }^{2}$ On the contrary, what I argue is that our personal and social identity can never be fully a result of our own personal subjectivities, and for that matter can never be fully dictated by structures of influence or control. While choosing to become tattooed, and while also drawing lines of reference to our identities from these tattoos, we must understand the dynamic role social actors take with regards to the practical consciousness of everyday life. As we will see, Giddens (1985), Goffman (1959), and Garfinkel (1967) offer a remedy to the dichotomy of subject/object by allowing us to understand that we are always, at once, both. Despite convincing arguments toward either side, such as that from the ultra-articulate Durkheim who illuminates the strong will to power structures of influence have over the body and the social actor, we must be constantly reminded that actors are always conscious and knowledgeable about themselves in society. In line with Giddens' “duality of structure" (1985: 25) structure is always serving as both enabler and constrainer.

\section{Methodology}

This research is qualitative and has been conducted through semi-structured interviews. My sample size is 15, with 11 female and 4 male respondents. I have focused primarily on persons who wear what I call "contemporary-style tattoo art." These intricately designed tattoos are representative of recent trends toward the professionalization and growth of complex designs in the field of tattoo art (Atkinson 2003: 46; See also "neo-traditional"). My participants form a non-probability, convenience sample which has been chosen because they represent a small group of enthusiasts who are highly educated (all are university students) and who encompass a variety of modern tattoo designs. These tattooees allow me to make claims about the polysemic nature of tattoo designs because they live these multiple meanings every day. This includes the ability to hide or show their tattoos if need be.

\footnotetext{
${ }^{2}$ Although I believe Atkinson understands the dynamic complexity behind social action as a contribution of individual, intersubjective, and objective influence, I also believe that my approach of using Giddens' structuration theory offers a more thorough exploration of these themes than is the case through Atkinson's exploration of Elias' figurational sociology.
} 


\section{Contemporary-Style Tattooee}

Narrowing my approach to studying contemporary-style tattooees has enabled me to discuss a sample population which is relatively articulate and culturally sophisticated. But what must be said about approaching a specific group of tattoo enthusiasts is that, although a primary interest in proving the shifting nature of cultural/social meanings of art has been tied to the goal of proving the usefulness of the term I have created, I do not wish to express this term as an authentically specific category used by tattoo enthusiasts. Rather, for the purposes of this research, the contemporary-style tattooee is someone who idealizes a broad variety of different time-sensitive designs that not only demonstrate a professional lineage in the art world of tattooing, but also necessarily demonstrate changing technologies and artistic professionalism in the field of tattoo design. According to Steve Gilbert who writes in Tattoo History: A Source Book (2000: 125):

The most popular designs in traditional American tattooing evolved from the efforts of many artists who traded, copied, swiped, and improved on each other's work. In this way they developed a set of stereotyped symbols which were inspired by the spirit of the times, and especially by the experiences of soldiers and sailors during the World Wars. Many of these designs represented courage, patriotism, defiance of death, and longing for family and loved ones left behind.

This remark parallels other studies which have noted so-called "stars" or "mavericks" in the tattoo art world who have contributed to the mass production and circulation of popular designs. Some popular examples include Lew “the Jew” Alberts (Atkinson 2003: 37; DeMello 2000: 54) and more recently Don Ed Hardy (Sanders 1989: 34; Don Ed Hardy 1999). While these stars of the tattoo art world have contributed to what Frankfurt School social theorists (among others) might typically devalue as inauthentic art, I wish to argue that authenticity is a useless category by itself as a single determinate of social action, distinction, or acceptance. I believe this is a valuable assertion primarily because of the shifting nature of meaning in tattoos, and also because from a structuration perspective we understand how authenticity should only be considered a reified system which influences tattoo enthusiasts' decisions by way of presenting itself as an often constraining structure (much like the "rules of the game" in Bourdieu's field), but is never the total reason for aesthetic choice or design. For an example of the types of discussion which devalue the contemporary-style tattoo 
design, we may turn to Adorno et al. who define art in a text titled Aesthetic Theory by stating that: "art keeps itself alive through its social force of resistance; unless it reifies itself, it becomes a commodity. Its contribution to society is not communication with it but rather something extremely mediated: It is resistance in which, by virtue of inner-aesthetic development, social development is reproduced without being imitated" (Adorno et al. 2004: 296). This discussion specifically argues that the productive use of defining art in such constraining ways serves only to contribute to Giddens' concept of the orthodox consensus of classical social theory which fails to understand the importance of the knowledgeable agent in contributing to social action (See Giddens 1979: 235-254; 1985: xv-xxxv).

\section{Analysis: The Skin and The Self}

By systematically discussing respondents' remarks and narratives and focusing on a few of their tattoos I wish to demonstrate the polysemic and complex forms meaning and identity take on with regards to tattoos. It is in the details of these indelible marks that "proof" will be offered supporting the idea that tattoos are complex mementos of the wild passions which have consumed our souls as individuals and as cultural actors. In these wild passions we see the influence of both structure and agency and therefore the need for a broad theoretical tool-kit from the social researcher in order to address tattoos in the context of the late-modern world. In discussing "wild passions," I am referring to Emile Durkheim's description of the reasons why actors use their body to display marks of their totem in The Elementary Forms of the Religious Life (1996: 232). But I transform the word to signify not just the heated impulses fed through group influence, but also the possibilities of human expression when tied with "true" emotions.

Part of my method will be borrowed from a study of material culture by Stephen Harold Riggins. Specifically I will be using concepts defined in the text "Fieldwork in the Living Room" as referencing and mapping. According to Riggins (1994: 109), the term referencing applies to an interviewee's remarks "about the history, aesthetics or customary uses of an object." Mapping refers to how actors use objects to plot "their social network, representing their cosmology and ideology, and projecting their history onto the world's map, its spatial spread so to speak." I believe these terms will prove a rich source for this study as they represent the cultural/historical and personal meanings connected to self-identity. When asking respondents to discuss the meanings of their tattoos, I often heard remarks mostly about the social ties and personal occasions tattoos represented (mapping). While this is ideal for qualitative research into the body, art, and tattooing, it is also of equal importance for 
myself, as the researcher, to provide intellectual authority on the referencing attributes of the same symbol. "...It is essential for the ethnographer to exceed the informant's often rather minimal level of referencing” (Riggins 1994: 109).

This analysis will be divided into sections based on the emerging themes from each collection of tattooees. The first people to be discussed are those who I will call the "social peacocks." These are the individuals who use tattoos in such broad social ways that they typify the contemporary style tattooee - able to adapt to any situation and to look cool while doing so. Their tattoos are sophisticated designs, reflective of the complicated meanings which are attached to them. These tattoos easily demonstrate multiple meanings from both a mapping and referencing perspective once interviewees are given the chance to do so. The second group of tattooees is the people who display "true" emotions, especially related to family. I argue, as does Atkinson (2003: 212-213), that a large part of becoming tattooed, and choosing the location and designs of the tattoo, is fueled by deep familial relations and ties. This will be evident in just how much mapping will be present in each tattoo analyzed in this section. Lastly, I will be discussing a collection of tattooees who represent issues around the body, sexuality, and gender. In this section, the topics of structure and agency are viewed once more as they aid in drawing out meaning behind tattoos and tattooees who are interested in things like beauty, femininity, and social acceptance while at the same time wishing to set themselves apart artistically through their body from constraints of their surrounding society. I believe these three themes of (1) social performance and knowledgeability of agents in crafting meaning; (2) deep and true emotions and the influence of family structures; and (3) the role of social and cultural aspects of gender, beauty, sexuality, and the body, are all ways of allowing my respondents to provide new discourses on what it means to be tattooed in the modern world. These themes will take readers into many different cultures, histories, and genres of thought. Tattoos are never about only one form of expression or social connection, but in fact are deeply human forms of social expression which have changed, and continue to record lives in multiple and complex ways. 
Figure 1.

\section{Roger}

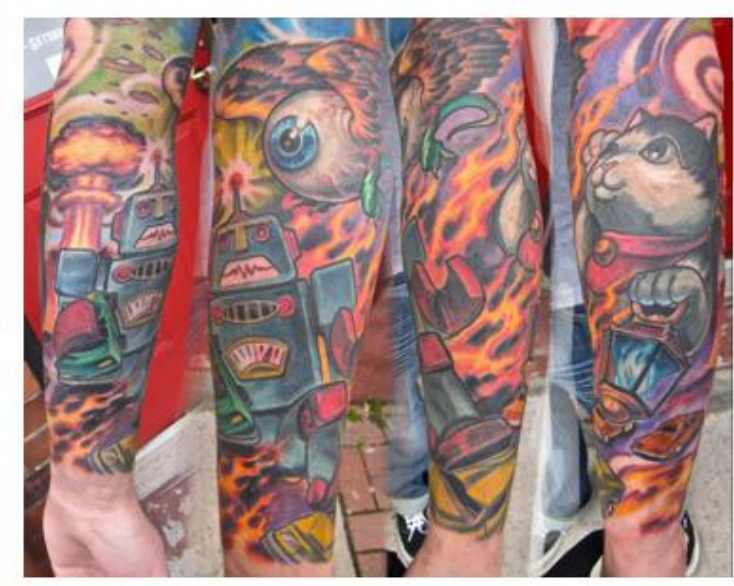

Photo: Left arm from four angles.

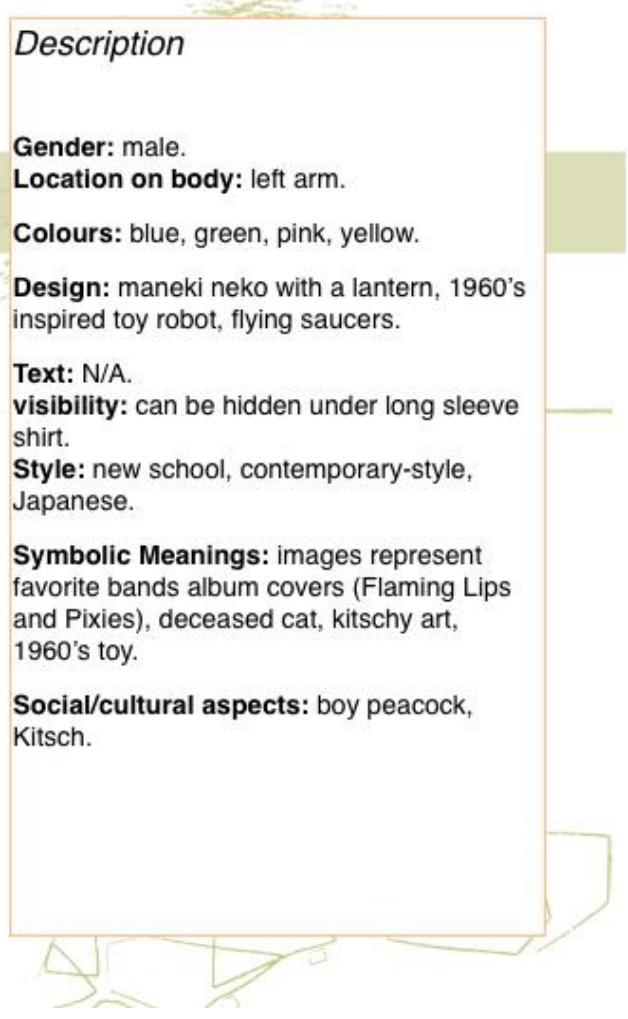

\section{Roger}

Roger has a large number of tattoos, although because of their connectedness, and engrossing nature, he refers to them as "two major pieces." As seen in Figure 1, Roger's two major pieces include the contemporary popular "tattoo sleeve" in which enthusiasts devote the entire landscape of flesh on their appendage(s) to being implanted with inks of various shadings. This inked devotion is most often linked with the goal of having a mural of artwork on an arm or leg which encompasses a primary style with a large number of different designs - all flowing together as a particular genre (Japanese, New School, Sailor Jerry, etc.). These tattoo sleeves represent an example of Lévi-Strauss's metaphor of the bricolage paired with what Tania Zittoun (2006: 128) describes as a collection of "cultural elements without a clear intention" where the tattooee is left to fill in the voids or complete the sometimes scattered image with meanings and personal elements of culture. For this study, it is important to note that I propose multiple meanings can only be exemplified - and never truly exhausted through a cultural, social, historical, and personal exploration by an external observer. 


\section{The Social Peacocks}

\section{Roger's Maneki Neko}

\section{Referencing}

According to William E. Deal in Handbook to Life in Medieval and Early Modern Japan, the maneki neko or "“welcoming cat' (was traditionally) used to greet customers at Edo-period shops and (was) believed to bring prosperity to the merchant (Deal 2007: 113). This reputation for greeting customers has made the maneki neko a symbol of a beckoning cat whose paws can mean either more customers or more money, depending on which one is elevated. As Roger notes, "It is a maneki neko, a lucky cat or whatever, I believe if he has a right arm up he is trying to lure in money, and the left is about bringing luck. I have the right arm up, but it is not about money." Further analysis of the maneki neko in the context of the Edo period would identify the piece as a product of a "blossoming urban culture of extraordinary richness, diversity, and originality" (Guth 1996: 11). Because the maneki neko is often present in Chinese businesses, many people incorrectly assume it is Chinese in origin. This is most likely a result of the idea that China is often noted as "Japan's cultural mentor" and because of the fact that "the intimate relationship between painting, poetry, and calligraphy that prevailed in China also characterized artistic expression in Japan" (Guth 1996: 11).

In the context of the art world of tattooing DeMello (2000: 72) places Japanese-style tattooing like the maneki neko in the hands of a few pioneering characters in American tattooing. "It was Sailor Jerry (Collins) who first introduced Japanese tattoo imagery and style to U.S. tattooists like Ed Hardy, thereby directly influencing American tattooing." According to DeMello (2000: 73), Sailor Jerry had an ongoing "trade relationship with Japanese tattooist Horihide (Kazuo Oguri)." For Roger, it is interesting to note that he has developed a great deal of pride in asserting that his tattoos are often made to strike a balance between the elements of being conventional and being unique. It is apparently important to Roger to control the meanings behind his tattoos and the ways in which others interpret them.

All of mine have coded meaning, but the thing is people grab my arms all the time and say "tell me what this means?" Since these meanings are codified, it is not always about telling everyone about them. The maneki neko, for example, has multiple meanings in that it represents a cat I had 
that died, but it also represents a Frank Black album called "Show Me Your Tears" which also features a maneki neko on the cover.

This type of contrast between traditional and personal influences is said to reflect the history of the Americanized Japanese tattooing style. According to DeMello, Sailor Jerry may have maintained a working relationship with Japanese artists, but he secretly held a grudge after the Second World War toward the Japanese. Because of this, he set out on a mission to use American imagery as a substitution for the focus images in traditional Japanese-style tattoos. DeMello (2000: 73) notes that Sailor Jerry believed “...what was exceptional about Japanese tattooing was not the center image but the background." This personal and cultural "give and take" is reflective of the power in the relationship between structure and agency as it serves as an intertwined precursor to social action. It is also a confirmation of the human complexities and contexts that exist on ink-marked skin.

The significance of the cat as the symbol in the maneki neko and in Roger's tattoo is in itself an interesting topic for discussion. As we will see in the mapping aspects of this tattoo, there are unique personal reasons why Roger chose the cat. But from a cultural aspect, it is worth noting Alger et al.'s Cat Culture: The Social World of a Cat Shelter. In this ethnography of a cat shelter, the social aspects of cats as members of cultures and groups of their own are discussed: "If cats can engage in such symbolic interaction, they will, given time, produce elements of culture or social organization such as norms, roles, and sanctions. That is, a group of cats over time in the same setting will produce a web of socially transmitted behaviors that constitute that group's solutions to its problems" (Alger et al. 2003: 48). If we assume that the connection humans have with pets will form another layer of symbolic interaction in itself, then we should imagine how humans can often become deeply connected with the same routines the pet has created for itself. This is significant in understanding both the human-pet relation and the deep connection humans can share with their pets as they become integrated into their daily lives as a living member of a culture of their own.

\section{Mapping}

The love of a pet can be a strong precursor to getting a tattoo. In fact, one of my latest tattoos is the boldly written name "Maxx" representing my cat that died last year. For Roger, the maneki neko has been given a distinct look from its usual all-white furry appearance. "It also reminds me of high school and hanging out with my friends and shit like that. I also had 
a cat that died that was black and white, so I go the tattoo to match her. Of course, I am white, so the white looks more pink." What seems to influence Roger most about his tattoos is their relation to his musical ambitions and obsessions. Music has played the role in his life that Riggins (1994: 113) calls a "social facilitator." It means that music is the avenue by which Roger has been able to interact with others and create friendships. In this same spirit, the tattoos also work as "time indicators" in that they act as indelible hubs of memory which can represent specific people, attitudes, and feelings. When asked "why music?" Roger responded: "the only thing besides, like knowledge or thinking about what to do next that can keep me up at night, is the idea of just thinking about music. Like it holds in memory, emotion and it is part of your life."

While we have seen the maneki neko serving the role of luring business customers, its cultural history does not give it the role Roger has intended for it. According to Roger, "I also got it so the cat was part of the destruction scene, where the robot is destroying the city and the cat is the light. Like the maneki neko saves the day." Another reading is that the cat holds a lantern like a human and might thus suggest Diogenes the Cynic (or Diogenes of Sinope, died 323 BCE), who supposedly carried a lantern in daylight looking for an "honest" man in Athens. Roger does not seem to be aware of this reference. The tattoo which forms a necessary part of Roger's sleeve is a deeply seeded sign of love and loss for a pet while it also represents the musical side of his life. For this reason I believe the mapping aspects of this tattoo, although not as overt as the potential referencing aspects, are held in high esteem.

\section{The Toy Robot}

\section{Referencing}

So, with the robot tattoo, I don't know why it is my favorite one. I think it's because I really like kitschy 1950's cultural things. The robot I have is based on a toy I had that was a reproduction of a 1950's design.

I am not sure of the history. It is just a very iconic robot and I date it to the 50 's based on other original toys like this I have seen on eBay.

After a search on eBay, I discovered that Roger had been relatively accurate about his dating of the toy robot. I also discovered that original toys of this design sell for up to $\$ 800$. Peer-reviewed information on vintage toys is hard to find. Independent research conducted by 
collectors tends to be the basis of information for such topics. As such, both webpages "Doc Atomic's Attic of Astounding Artifacts" and "Attacking Martian" claim the original tin robot toy is a product of the "Yonezawa Toy Company" based in Japan. Its name is "Smoking Robot" and it is popularly considered to be a toy of the early 1960s. The following pictures are from a 1963 catalogue of toys produced by the "Yonezawa Toy Company" collected from the "Attacking Martian" webpage. The close-up image is the toy purchased by the author of the blog "Doc Atomic's Attic of Astounding Artifacts."
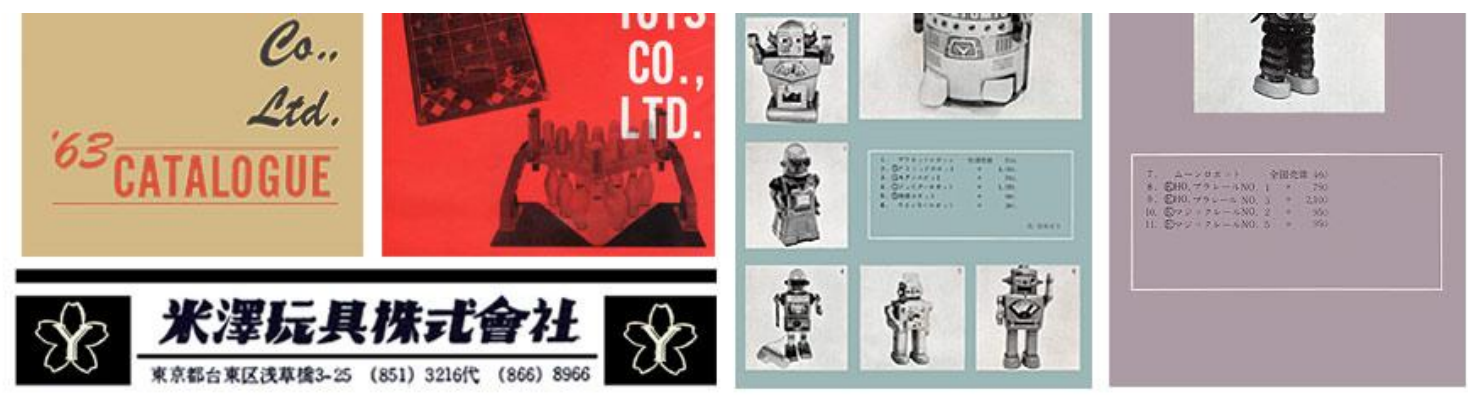

Figure 1.A.

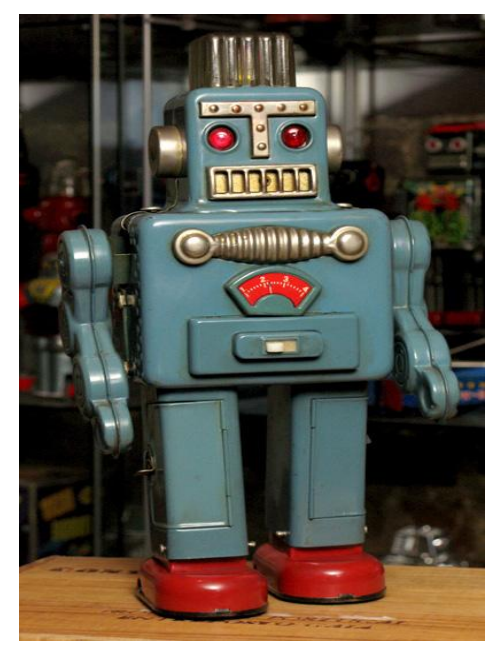

Figure 1.B.

According to James Allen Dator in Social Foundations of Human Space Exploration, at the time when these robots were designed and manufactured space exploration was on the horizon. "Space was then for visionaries and dreamers, an alluring fantasy from the everexpanding future" and it was "an arena for adventure and romance" (Dator 2012: 32). Over time, however, space travel would evolve into an arena for Cold War rivalry. “... Since the days of the Cold War, the stern cultures of the military, government, and military-aligned businesses have taken over, and wrung all the fun and fantasy out of the enterprise. Space 
now is about rockets, wars, and jobs, and not about visions and transcendence" (Dator 2012: 32). Roger shares an affinity for the romance and wonder of space. This can be noted in his tattoos of flying saucers. But instead of identifying with space travel, Roger explains his attraction to these types of images as a deep interest in "kitsch." Whereas the mysteries of space may once have been a source for romance and science fiction, Roger (like many others) has now relegated fantastic stories and speculative images such as the space robot to the world of kitsch. "So, with the robot tattoo, I don't know why it is my favorite one. I think it's because I really like kitschy 1950's cultural things. A lot of this again is about the 1950's kitschy art thing."

Esther Leslie defines kitsch in her analysis of the philosopher Walter Benjamin by noting Benjamin's understanding of this new form of "art" as a practice in the resiliency and commodification of capitalism. "Developed are new techniques of using this industrialized material - entertainment devices, cheap prints, ornaments and the rest. Novel objects, massproduced kitsch commodities, force themselves on 'the new person,' jostling for attention in cluttered environments. Kitsch and clutter, abortions of industrial technological developments, demand the right to existence and love" (Leslie 2000: 11). A similar critique of kitschy art is found in Clement Greenberg's essay for the Partisan Review titled "AvantGarde and Kitsch.” In Greenberg's critical cultural analysis we see his distaste for the kitschy as it takes its place at the cultural table as the antitheses of the avant-garde.

Where there is an avant-garde, generally we also find a rear-guard. True enough - simultaneously with the entrance of the avant-garde, a second new cultural phenomenon appeared in the industrial West: that thing to which the Germans give the wonderful name of Kitsch: popular, commercial art and literature with their chromeotypes, magazine covers, illustrations, ads, slick and pulp fiction, comics, Tin Pan Alley music, tap dancing, Hollywood movies, etc., etc. (Greenberg 1939: II Para 1).

Readers should recognize the struggle for true authenticity in Greenberg and Benjamin's writings. Critical theory and cultural criticism which have Marxism as their foundation maintain that true emotion cannot exist in kitsch. The only exchange is that of cold, hard cash. These perspectives look at the impact of structural determinism on choices of social action 
and on the practice of art/tattooing. The personal meanings which counter these arguments can be found in the mapping aspects of the tattoo art.

\section{Mapping:}

The toy had been a gift from a girlfriend at the time and when I was getting the tattoo I gave the toy to my artist who had other toys in his shop anyway.... It is also my (current) girlfriend's favorite tattoo.... You know also she was doing a presentation one time recently and she was really nervous. So I ended up buying her a pen with the robot on it as a way of cheering her up.

The mapping aspects of this piece, as is the case with many other tattoos which will be discussed, is the level of meaning which illustrates human agency as part of the act of getting a tattoo. The preceding quotation, which draws out the influence of multiple partners on Roger's choice of tattoo, conveys an impression of intrigue. An interest in kitsch is a choice to adore art which is not a fine art. In such a perspective we may include Roger's use of otherwise kitschy or disregarded art as a tool for personal expression as an example of the concept of "alien use" (Riggins 1994: 112). This is because the manufacturers of the toy robot, the countless reproductions of it, and the cultural fad of space travel have all contributed to the current social and personal meanings Roger attributes to the design, even if this was never meant to be the original purpose of the toy robot. This shows the polysemy that is inherent in material artifacts and in inked artifacts. An even better example of alien use in this design can be found in the comparison between the enjoyment of this tattoo by Roger's partner and his description of the interaction of everyday life as a tattooed man. "Without a doubt ... there is no girl who I've been with who hasn't liked my tattoos. It's like you're a boy peacock and they like your feathers.... You can call it a sort of sexual insurance." The ability to use one's body as a form of expression is not limited by the authenticity of designs. For Roger, what may constitute inauthentic art to some people has now shifted to an interesting and exotic category of kitsch transformed into highly decorative tattoo art. 


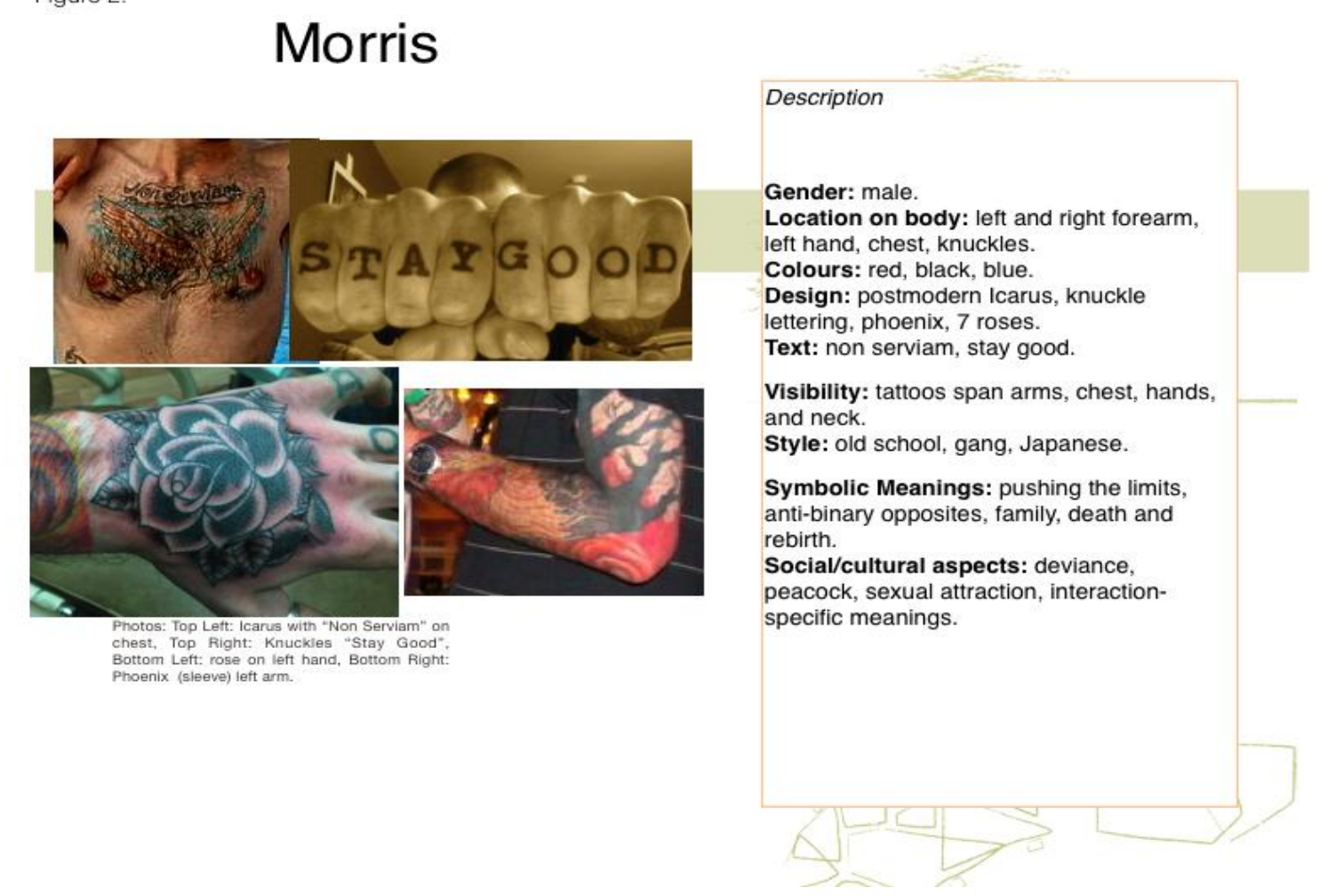

\section{Morris}

My interview with Morris was one of the most interesting and challenging. This is partly because he is a graduate student studying English literature and philosophy, which means that he supplied an uneven mix of referencing and mapping perspectives on his tattoos. Although this may seem like a good thing, it is important to complete an interview with a large stock of examples of mapping. Unlike referencing which can be obtained from books and the Internet, mapping comes from only one source, the interviewee. It was also difficult for me to see the significance of some of the comments I was given until I conducted further research. Morris is one of several examples of a person giving coded meanings for his art which reside in very specific and culturally sophisticated sources. Because of the variety of meanings and mapping/referencing aspects I was given by Morris, I am forced in this case to refer to Morris' tattoos more broadly rather than to specific tattoos at a time. In exploring the referencing aspects of his tattoos I will discuss Morris' Icarus and his four-leaf clover. In regards to the mapping aspects, I will focus on his mother-inspired tattoo and with his relations with others. 


\section{Morris' Postmodern Icarus, Four-Leaf Clover, and his Mom's Roses}

\section{Referencing}

Well, the story of Icarus and Daedalus is about a father who builds wings for his son to escape the labyrinth but tells him not to fly too high because the sun will melt the wax. But we did Icarus in a postmodern pose because he looks like he is doing more of a Led Zeppelin pose rather than a traditional man with wings. It is also a reference to (James) Joyce, and his character Stephen Dedalus in his Portrait of the Artist as a Young Man. It goes back to the idea of pushing it too far. Don't go too close to the sun, but he does it anyway. This is a symbol I associate with coming of age, with art. Take it too far, always take it too far. Fuck whatever instructions. This is the symbol for the artist. Don't follow instructions and at the end of the day you'll end up doing what you want to do.

There is a line in the book Portrait of the Artist as a Young Man which is Latin that says: "non serviam." It means "I will not serve." There is a famous idea of Joyce leaving the Church of Ireland and saying this. It is in the book and it is known to be the words Satan spoke when he left Heaven. And Joyce was never the one to shy away from pride.

I begin this section of referencing Morris' Icarus tattoo with the above quotation because the idea of "pushing limits" placed on yourself and by others in society is without a doubt a theme that transcends all of Morris' tattoos. It is a message that is represented in the Latin words that Morris has tattooed in script on his chest which says "Non Serviam" (I will not serve). It is characterized in Morris' admiration for the idea of the artist as someone who slips into a life of questioning that which has been laid out before him or her and that which is virtuous and necessary in creating art.

In James Joyce's Portrait of the Artist as Young Man, a book that has influenced Morris' opinions and tattoos, the protagonist Stephen Dedalus writes of a life contemplated by the influences of structures of control and the possibilities of structures influenced through epiphanies. For Dedalus, the journey to consider himself an artist leads to the claim "I will not serve that in which I no longer believe, whether it calls itself my home, my fatherland or 
my church: and I will try to express myself in some mode of life or as art as freely as I can and as wholly as I can, using for my defense the only arms I allow myself to use, silence, exile and cunning" (Joyce 1928: 291). These words are powerful because as Morris noted "I will not serve" has a strong connotation for a person willing to abandon a religious upbringing in the pursuit of art. It is also popularly associated with the devil and deviance. As Joyce noted earlier in the text before his epiphany of watching a beautiful girl "paddling in a stream with her skirt hiked up" (Joyce 1928: 108):

Lucifer, we are told, was a son of the morning, a radiant and mighty angel; yet he fell: he fell and there fell with him a third part of the host of heaven: he fell and was hurled with his rebellious angels to hell. What his sin was we cannot say. Theologians consider that it was the sin of pride, the sinful thought conceived in an instant: non serviam: I will not serve.

Throughout this article, I have been stressing the importance of structure and agency as dual antecedents to any social action, including becoming tattooed. This is because, in line with Giddens' duality of structure, there is always a consequence to action which affects and is affected by structure. Structure is the means and end to an action. I refer to these theoretical ideas here because there is always a reaction to any action and thus pushing limits in the pursuit of art or otherwise will surely have an effect and this may not be the ideal outcome of the conscious intent. While listening to Morris' description of his tattoos, I felt I had to ask how his neck and hand tattoos might affect his ability of getting by and performing different roles in everyday life. Like Joyce, Morris displayed a certain and intentional, although bittersweet, satisfaction in having pushed the limits he set on himself, including where to get tattooed.

This four-leaf clover on my hand I got after coming home from Las Vegas when I won some money and I was on a rush. I went down to my artist and told him and he was like cool, but are you sure? People say get them, but avoid your hands, neck, that kind of stuff. But I got this anyway and 2 years later I have my neck and both my hands tattooed. It was a big one to get for breaking the barrier. 
This idea of the consequences of action is also important in the cultural and historical significance of the classical Greek myth of Icarus. This is because Icarus is not always seen as a symbol for the virtue of pushing the limits. It is important because there is a contradictory nature in Morris' caviler attitude toward rules and structure "I see the value in structure, but I don't think it has any transcending or guiding principle."

In Wallace and Hirsch's Contemporary Art and Classical Myth, Sharon Sliwinski (2011: 199) draws a powerful comparison between the image of The Falling Man on 9/11 and Icarus. The photograph of the man jumping from the World Trade Centre in New York City on September 11, 2001, has become an image which is implanted in the minds of those who have experienced it. I say “experienced it" because as Sliwinski notes "Drew's picture is certainly mesmerizing - the calm, arrow-straight position of the figure's body, the uniformity of the background, the overwhelming sense of negative space. But the perturbation one feels when gazing upon the photograph comes from elsewhere. And it is considerably harder to speak of this perturbation that it is to speak of the picture's formal properties" (Sliwinski 2011: 201). Although the image and the myth of Daedalus and Icarus have been reproduced countless times, Sliwinski notes the 1606 woodcut by Antonio Tempesta titled The Fall of Icarus as the most notable and striking comparison with The Falling Man. According to Sliwinski (2011: 208), who recites the classical myth: “Icarus disobeyed his father's instructions and began to soar to greater and greater heights, rejoicing on the lift of his great wings ... spectators of this image once again find themselves witness to a horrifying plunge. Icarus' face is turned away from us, his robes flap helplessly in the wind, his arms and fingers stretch outwards in that unmistakable gesture of one who is falling a long, long way." Our mortality, our ambitions, and our connectedness are all evident in these images. This comparison may be a stretch in some regards, but the images which define human history are those which often lead to the same themes and messages. For Morris, it is curious to wonder about both the virtues and the potential negative consequences he may experience in "pushing the limits." 


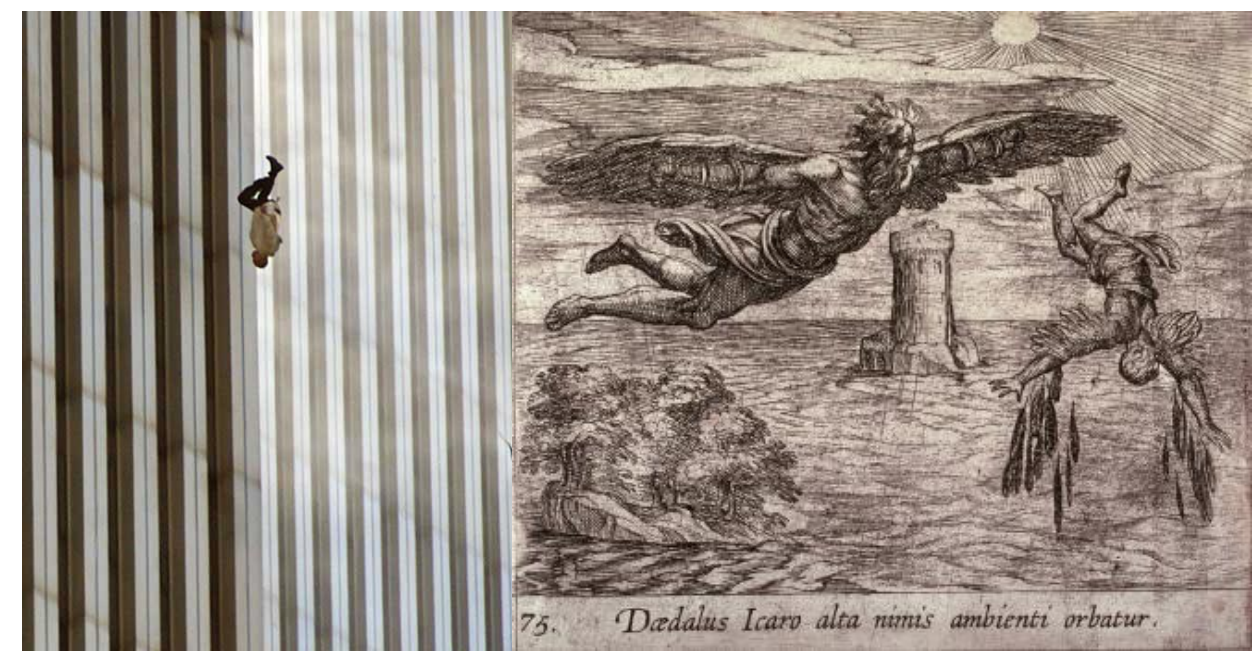

Richard Drew (2001), “The Falling Man” http://www.esquire.com/features/ESQ0903SEP_FALLINGMAN

Antonio Tempesta (1699), "Daedalus Icaro alto nimis ambienti orbatur (The Fall of Icarus)." http://popartmachine.com/art/FASF-FASF.58478/function.pg-connect

\section{Mapping}

I began my interview with Morris who is heavily tattooed with a novel approach which occurred to me by trial and error through interviews with other tattooees. I asked him to tell me his favorite, and from there I circled around his skin canvas to explore others. To my surprise, Morris had an answer right away to my question of his favorite. His response was: "Ah my mom, I got a tattoo a couple of years ago for my mom. Just the story around it makes me think of it as having the most meaning. I enjoy my tattoos, but this one sticks out most." He gives this tattoo the most significance of any his tattoos. The meaning is an example of mapping. It is a tattoo which we can understand through what Riggins' (1994: 112) terms an "esteem object" as it represents a perceived gratified feeling and respect for both his parents and what they represent.

It's her name and seven roses. It comes from a story my dad explained to me when I was younger. He told me that when he first met my mom he was trying to court or woo her, or some crap. Anyway, he was trying to buy a dozen roses but he couldn't afford them. So he thought of buying six but 
decided that it would be too clichéd, so he waited and saved enough money to buy the seventh one. Now every year, on their anniversary, he still gives her seven roses. It's like going more than what you think you should do and making something your own. It's like, "fuck the status quo."

The importance of meaning was very evident in Morris' description of both family and of social interaction. In regard to interaction with others in everyday life, Morris maps out the relation he has with others who have not necessarily been reflective of the original meaning he intended for his tattoos but those who have been involved in the renegotiation of what his tattoos mean to him over time.

I go with traditional styles of the rose but it is not as much about the image as it is about the symbolism and the way you arrange them. And maybe it is because I am a nerd or an English student but I feel that the meaning kind of improves as you grow. Maybe the meaning I had when I first got the tattoo is different now. On the other side of the coin, how easy it is to make up a story when you are in a bar and you don't want to talk to someone about your tattoos. I've come up with some pretty fun stories.

The chance to hear a story of meaning, one which was made up to suit a social interaction and one which has had Morris reflect upon it as a necessary part of further social interaction as a heavily tattooed individual was an opportunity I could not pass up. This story is an example of Garfinkel's ethnomethodology of interaction and of Riggins' (1994: 113) concept of social facilitators.

Well, I don't know exactly what I said, but the situation was a lady in a bar that was far too drunk and I am not sure if she was hitting on me or whatever but she was fascinated by my tattoos. I was uncomfortable and she was touching me, so basically I told her I got these in prison. "This one is for time served," you know, whatever. 
Morris' tattoos have pushed the limits on my knowledge of contemporary art and classical myths. For this reason, I count his tattoos to be some of the most complex designs, irrelevant of their actual detail which, as can be noted in Figure 2, is also quite extensive.

\section{Morris and Social Theory}

Morris, who considers himself to be an anti-Structuralist and even used this perspective to plan out his ink art, discusses his opposite tattoos like the grim reaper on his left forearm and the phoenix on his right forearm by saying: "And I kind of like how they are opposites but not exactly. In my academic life I am always hearing about binaries. I don't know if that's an influence of Derrida in there. But it is nice to not have exact opposites." The same sentiment is shared about his knuckle tattoos, which are another example of crossing a line of limits. "A lot of people get opposites on their fingers, but I didn't want to. I was like fuck that." These statements, coupled with the stories of interaction and the role his tattoos have in everyday life are important points in understanding Morris' tattoos and their meaning, especially if we substantiate the point through similar perspectives emphasized by Anthony Giddens and structuration theory. This is because like Morris' ideas about the meaning behind his “anti-binary opposites," Giddens' idea of meaning production is also an anti-Structuralist perspective. Kenneth Tucker (1998: 79) notes that "according to Giddens, social meaning does not simply derive from differences in enclosed linguistic systems, as many in the Saussurean tradition argue. Like Goffman, Giddens contends that meaning is bound up with practical activity in the real world. Giddens states that an adequate understanding of meaning must be tied to the ethnomethodological 'use of methods' embedded in practical consciousness."

\section{Familial Hearts and Ink Marks:}

\section{If their Stories are True, their Truth is a Story}

It is important to note that while I will discuss "true" emotion in this collection of tattooees, the word truth is not meant in a traditional sense - if such a sense can really exist denoting a true value as opposed to false or incorrect lesser values. In fact, I use the word to illustrate the polysemic nature words, symbols, and phrases possess. In my interviews I aimed to see, listen, and record what I know to be honest emotion. These feelings like love, hope, loss, and redemption come attached to the ink marks on my respondents. These feelings form 
stories which encompass a part of my interviewees' lives and embody memories which have been, and continue to be, influenced by the shifting nature of identity, meaning, and time.

Family is one of the powerful reasons given by tattoo respondents as a motivation for becoming tattooed and in choosing where to get tattooed. One hundred percent (15) of my participants listed family as part of the mapping aspects of at least one of their tattoos. The following respondents literally embody a love and kinship for family that was so strong it needed to be made permanent and part of their cultural repertoire. Tattoos are so often about being in dialogue with one's self and with others. Thus these family-inspired tattoos influence social interactions and the looking-glass self (Cooley 1998) aspects of these tattooed peoples' lives in an infinite number of ways.

\section{Élise}

An example of this blend of raw emotion and ink-marked skin comes from the next research participant who I call Élise. Élise has the entire left portion of her torso stretching right down to her thigh and up towards her shoulders marked by what she sometimes calls a "fallen angel" and at other times a "seraphim" (Figure 3). 


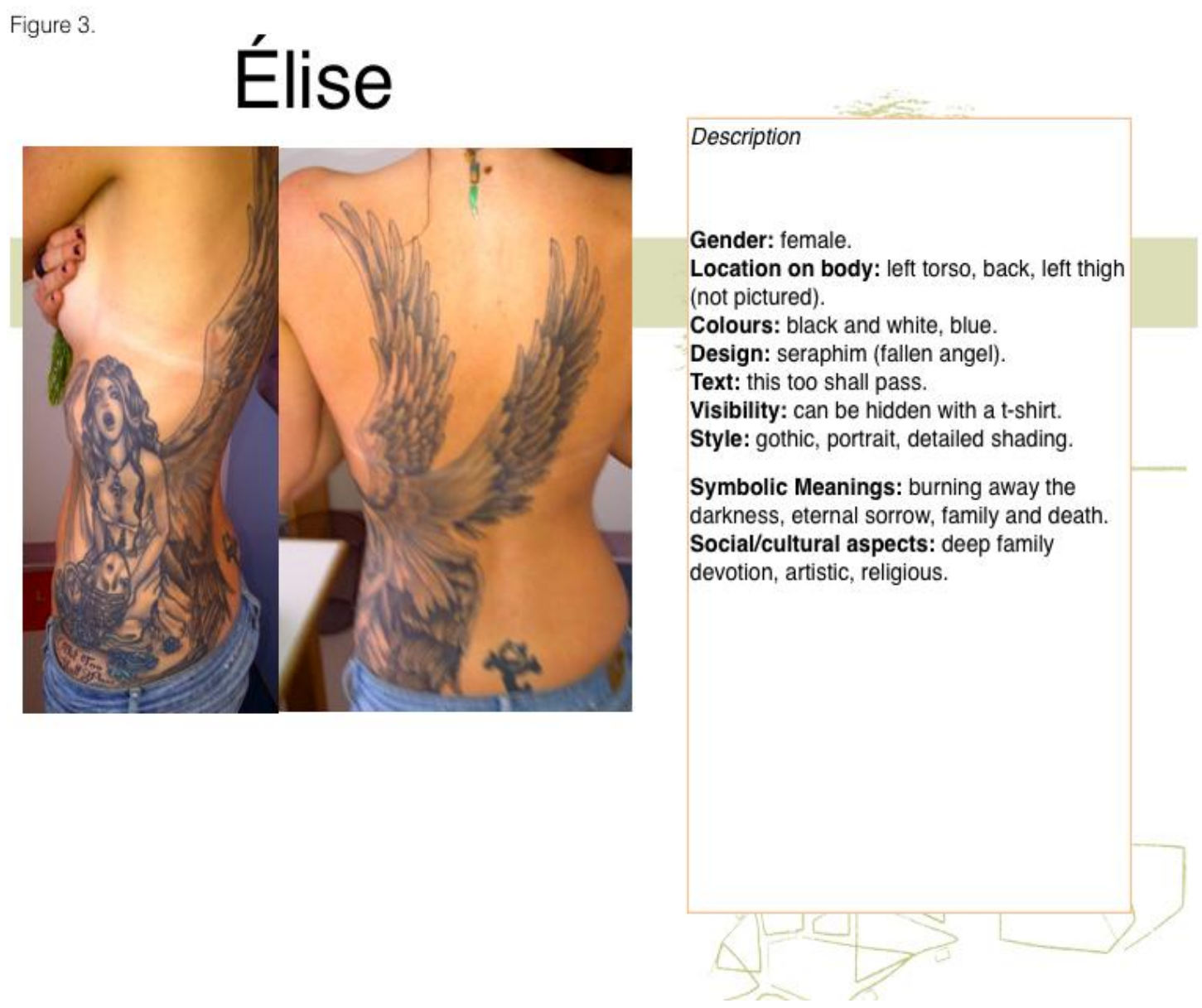

\section{Referencing}

According to the classic theological text Celestial Hierarchy by Dionysian, a seraphim “destroys and dispels every kind of obscure darkness." In Élise's case, the seraphim whose task is to dispel darkness through light, and the profane through the sacred, has been made permanent on her skin with an array of mostly black and white shading with an artistic, and emotional splash of richly coloured blue ink. The piece, which was drawn partly free-hand and partly stenciled, is a very intricate example of a contemporary-style tattoo because it beautifully blends traditional and new designs while also demonstrating an increased professionalism in artistry, depth, shading, and close attention to details. For Élise, the primary meaning of this tattoo is not its aesthetics but its symbolism.

\section{Mapping}

In line with the mapping aspects of her conversation, Élise tells me how the angel is meant to be a memorial to two siblings who passed away at young ages and are evidently deeply missed. 
The wings are tattered and broken. Her face is in anguish and the flowers are blue because it was my brother's favorite color. It is the only color in the tattoo. I have script running down my thigh that says "this too shall pass".... I took my brother's goalie mask and asked the artist to have the mask rest on the angel's lap. She is weeping over it.

For Élise, this piece is a container of memory, a painful display of emotion, a sign of love, and a representative of her artistic side. The tattoo takes on multiple meanings and gives other people a different image of her, which will indefinitely influence the way they view her body, and in turn, the way she views herself. Thus I tend to view Élise's seraphim as completing the ingredients of a structuration perspective on understanding the role a social actor plays in being both enabled and constrained by social structures while, at the same time, knowingly conveying a specific personal meaning that is not fully evident by looking at her tattoo. She has to explain the autobiographical dimensions. Élise is creating new meanings for herself and her family while still being influenced and shaped by others, namely through social definitions of art, beauty, love, and the capabilities of the institution of tattooing.

\section{Jerry}

Figure 4 shows about half of the tattoos on "Jerry's" body. The rest runs down his thigh and ends on his calf. The blend of styles, colours, motivations, meanings, and their relation to his identity has led me to count Jerry as one of the Newfoundland enthusiasts proving the complexities tattoos can carry, especially related to the way he connects them to his home and family.

\section{Referencing}

What is visible in this picture are famous images from the vicinity of St. John's, Newfoundland, which reflect the referencing aspects of Jerry's talk. The tattoos depict the Cabot Tower, "jellybean" coloured row houses, a humpback whale, and the fickle twilight sky. These tattoos represent ideas that have long been considered a source of intrigue to cultural scholars interested in Newfoundland (Overton 1988, 1996; Sider 1980; Pocius 1988). This is Newfoundland's eclectic cultural and social history and its role in providing a source of pride and a burden of responsibility to Newfoundlanders as they function as gatekeepers of the province's tradition and heritage. James Overton (1988: 6) writes that "a number of 
intellectual patriots have been involved in cultural regeneration, claiming to be articulators of the collective unconscious of Newfoundland. They have attempted to come home to Newfoundland's distinct culture, searching for it, discovering it, surrendering to it, recording it, defending it, preserving it, promoting it, reviving it, and drawing inspiration from its artistic work." Overton writes so detailed and succinctly about the ongoing process of culture building and maintaining that Newfoundlanders' employ as a way of stressing the importance place can have for those involved with collective negotiations of self, culture, and belonging. In fact, Overton (1988: 6) also notes how "culture is on the march in Newfoundland....

References to tradition, culture, way of life, identity, lifestyle, and heritage liberally sprinkle the newspaper columns, the pages of various small magazines, the speeches and slogans of politicians of all stripes, and the lyrics of popular songs." Readers may note the large number and subject matter of Jerry's tattoos relating specifically to Newfoundland as a useful illustration of this type of patriotism and task in maintaining Newfoundland culture and spirit in a permanent way.

Figure 4.

\section{Jerry}

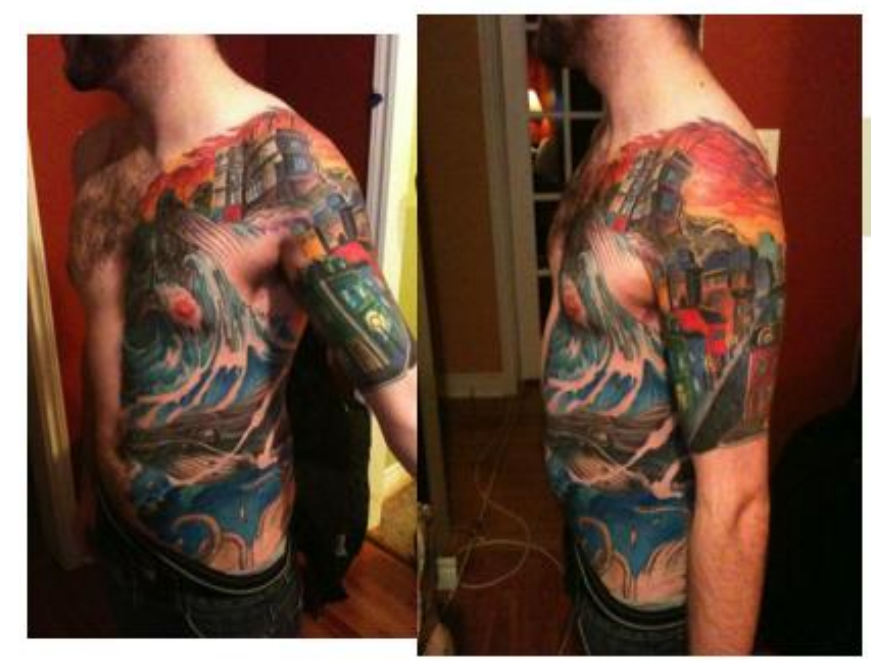

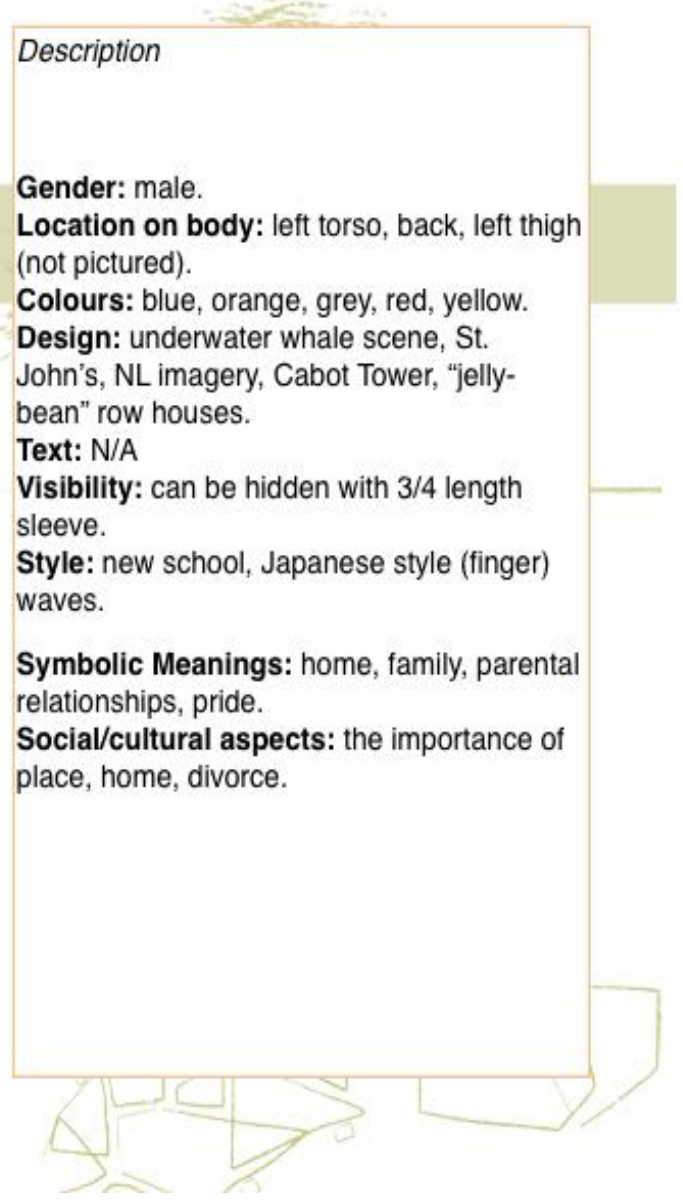




\section{Mapping}

What is not visible in the image is the way Jerry maps his family, his childhood, and his views on the socialness of tattoos. Here is what Jerry says, while referring to the underwater scene on his stomach which can partly be seen in this image: "I love whales, so I got some whales... I got some lobsters, you know, cause it reminds me of home. You know my dad [who divorced my mother] was a fisherman. So I'd get lobsters as a form of child support. The whales and lobsters were also ways to make my underwater scene unique, and the whales make it like even more of a fucking St. John's scene.”

Repeatedly and voluntarily, Jerry talked about his family in relation to his tattoos. When asked if others like his tattoos, his comments gravitate toward family rather than art history. When asked if he thinks tattoos are becoming more popular, he discusses his mom's unexpected desire to get a tattoo. Despite all of this talk of family, his father was only mentioned once and then only with a sarcastic remark about his inability to provide for his child. All of these remarks contribute to Jerry's identity, his pride in Newfoundland (specifically his small home community), his pride in family, and his wish to be unique. All provide an in-depth look at his self-identity as it has been recursively affected by others. Importantly it also describes how Jerry views his body as a vehicle to display such complex sentiments: "I was like, fuck it. I'll just use my entire body. I can't just get one tattoo."

\section{Beauty and Art: Gender, the Body, and Self-expression}

To recap, the social peacocks have allowed us to see the creative and expressive nature of human agency in conversation with others. The familial hearts in ink marks demonstrate the enabling aspect of group or structural influence. Now it is time to view another category of tattooees who fully demonstrate both the enabling and the constraining aspects of structure which influence their ability to commit themselves and their bodies to becoming tattooed. To be clear, this means that although tattoos are representations of both our wild passions which define us and mementos of ephermal moments which populate our lives - they are also influenced by the cultures which we live in / live through and by Fine Lines (Zerubavel 1991) which are drawn as objective realities in culture and come to form real consequences in our lives.

These Fine Lines, as Eviatar Zerubavel points out in cognitive sociology, are the lines social actors draw in their minds in order to interpret the world from different objective realities. Where we - as a social collective or culture - place the line, influences and begins a 
cycle of acceptance, repetition, and finally the construction of a new reality which forms "real" consequences of its own. "Separating one island of meaning from another entails the introduction of some mental void between them. As we carve discrete mental chunks out of continuous streams of experience, we normally visualize substantial gaps separating them from one another" (Zerubavel 1991: 21). In other words, "the lines drawn in the sand" by the cultures we live in come to form boundaries and levels of acceptance for social phenomena. This is the experience of the tattooed individual. While the line is constantly withdrawn and constructed again, tattooed individuals can often be subject to real consequences from social laws (Tarde, as referenced in Ruitenbeek 1963) that do not really exist. Social Laws by Gabriel Tarde, a contemporary of Durkheim, is mentioned here because the epistemological description of science and the resulting creation of social laws that Tarde explores in this pivotal work, I suggest, are mirroring processes to the development of Zerubavel's fine lines. As Tarde notes: "thus science consists in viewing any fact whatsoever under three aspects, corresponding, respectively, to the repetitions, oppositions, and adaptations which it contains and which are obscured by a mass of variations, dissymmetries, and disharmonies" (Tarde, as quoted in Ruitenbeek 1963: 101). These concepts will become more clear when we focus on the tattooed individuals who will be discussed in the final category of analysis for this article. These tattooees are the people who openly shared their feelings with me about what has influenced and continues to shape their roles as social actors in deciding to become tattooed, where to get tattooed, and the appearance of their tattoos.

Not everyone can get tattooed. It is costly. It is painful. It is increasingly regulated by age and by shop practice. And it is also a permanent corporeal commitment which can impact the life not only of tattooees but also the people they will interact with in the future. As $73 \%$ of my sample (11) is female, gender is a good starting point in discussing the constraining aspects of structure. Sociologists from the symbolic interactionist tradition (Blumer 1969, Goffman 1959) make it perfectly clear that the desire to look favourable while interacting with others is an inherent part of what it means to be social. Anthony Giddens (1991: 100) provides an interactionist-influenced perspective on the reflexive self which focuses on society's constraints on bodies: "Not only must an individual be prepared to interact with others in public places, where demeanour is expected to meet certain generalized criteria (fine lines) of everyday competence, but he or she must be able to maintain appropriate behaviour in a variety of settings or locales. Naturally, individuals adjust both appearance and demeanour somewhat according to the perceived demands of the particular setting." Similarly, the ideas of Michel Foucault are of key importance in understanding biopolitical 
influences on our bodies. While discussing discourses on medicine and proper care of the self, Foucault (1986: 100-101) notes “... whether we are walking or sitting, whether we are oiling our body or taking a bath, whether we are eating, drinking - in a word, whatever we may do, during the whole course of life and in the midst of life's diverse occupations, we have need of advice for an employment of this life that is worthwhile and free of inconvenience.” These remarks, put the following narratives under a lens which clarifies not only the expressive human agency in getting a tattoo, but also the world of structural influences which constrain and enable our decisions and how we live with the consequences of these fine lines or social laws. Although I believe it is always important to see the subject in the constitution of social action like getting tattooed, it would also be irresponsible to ignore all the men, and particularly woman, I talked with and who provided stories about outside influences on their body and their concept of gender.

\section{Rachael}

While discussing her family's reactions to her tattoos, Rachael adds a gendered perspective on her tattoos. And although it is clear from her words and non-verbal expressions that her family's opinions about her tattoos are important to her in many ways, it is also clear that Rachael has a certain desire to break the gender barrier and in the words of Betty Friedan in the pivotal Feminine Mystique (1963: 73) provide "an act of rebellion, a violent denial of the identity of women as it (has) been defined ... to shatter, violently if necessary, the decorative Dresden figurine that represented the ideal woman of the last century." The language used in feminist scholarship is powerful and emotion-provoking because that is necessary to provoke change and new modes of thought. Rachael counters the feminine images of the past, alluded to in Friedan's work, by noting: 
Figure 5 .

\section{Rachael}
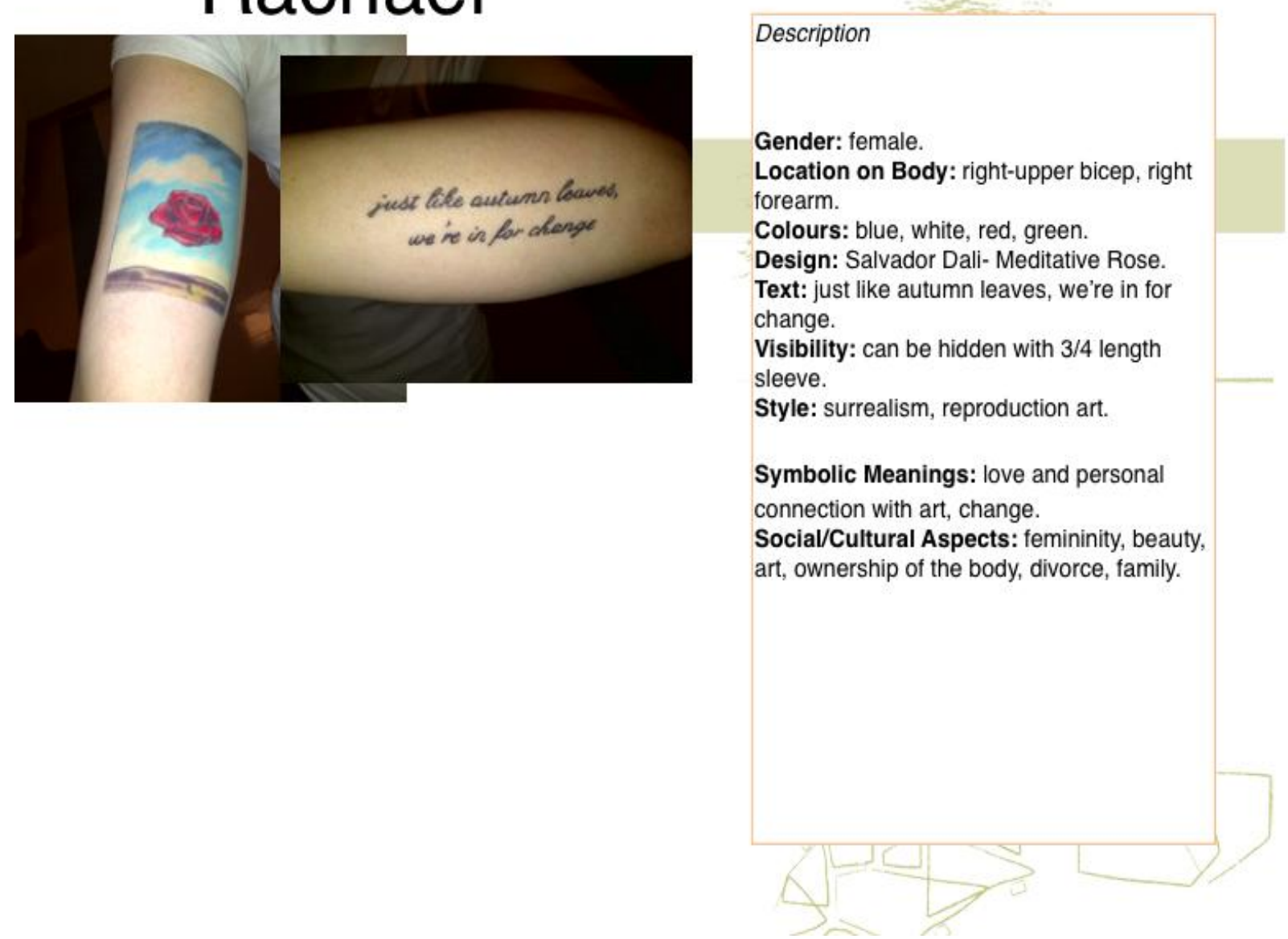

I get some good and some bad (reactions to my tattoos). And the bad mostly come from my family. Like a lot of people are interested in the tattoos, but others not so much. My grandmother called me "damaged goods" when I was 18. She looked at me and said "who is going to marry you with your body like that?" My father also sighs every time I tell him I have another one. But I didn't need him. Around the time I started to get them my parents were getting divorced. I think he doesn't like them because he wasn't part of the discussions my mom and I had about getting them. 
With my grandmother I could never really get a chance to tell her what they meant. It doesn't really even make any sense because I have male cousins who have tattoos and she doesn't really say anything to them. I am the damaged one. And I don't want to have to justify myself to anyone. These are for me.

With these remarks in mind, we may begin to reference and map two of Rachael's tattoos so we can come to appreciate how the social and personal are reflected in her tattoos. In their aesthetic, their placement, and their meanings, Rachael's tattoos say something about her desire to express her own interests and also the enabling and constraining structures limiting her options.

\section{Rachael's tattoo of Salvador Dali's Meditative Rose}

\section{Referencing}

Surrealism is a unique genre of painting, literature, and poetry that emphasizes the logic of the illogical, the "logic" of dreams, for example. According to Modern Art 1900-1945: The Age of the Avant-Gardes: "Given its anti-logical and irrational character, contrary to all codification and hostile to rules and hierarchies, the surrealist movement had no homogenous or unitary structure; it can be said that there were as many surrealisms as there were artists who, to a greater or lesser degree, made surrealist art" (Crepaldi 2007: 207). But a more precise definition of the art form can be taken from André Breton's 1924 Manifeste du Surréalisme which defines surrealism as "psychic automatism in its pure state, by which one proposes to express - verbally, by means of written word, or in any other manner - the actual functioning of thought. It is dictated by thought in the absence of any control being exercised by reason and is exempt from any aesthetic or moral concern" (Breton, as quoted in Crepaldi 2007: 206). Salvador Dali (1904-1989) was an eclectic and controversial artist who is commonly associated with surrealism. An example of how Dali's work has been discussed as surrealist art can be taken from the book Dali and Surrealism:

Within a highly sophisticated and carefully structured pictorial mental landscape (Dali) used devices to create formal visual analogies for the experience of dreams and hallucinations.... Odd or apparently illogical 
connections are made between disparate objects or groups of objects, and people or things can metamorphose unexpectedly into something else, for no apparent reason (Ades 1982: 75).

Influenced by the work of Sigmund Freud, Dali used surrealism to explore one of the most potentially illogical forms of cognition: dreams. Moreover, a reason why Dali's work is considered surrealist can be drawn from the general cultural dissent and marginality he was said to have felt. According to Dali in the book Dali by Dali "I have always been an anarchist and a monarchist at the same time. Let us not forget the two founders of anarchism were Prince Kropotkin and princely Bakunin. I am, and have always been, against the bourgeoisie" (Dali 1970: 64-65). The spirit of surrealism is one which has far-reaching influences.

Surrealism has been quite influential in mid-twentieth-century French culture. Paul Bouissac, French intellectual and Structuralist - known for studying the unconscious logic which governs the culture of the circus (See Bouissac 1985, 2010) - candidly discusses the impact the surrealist movement had on his intellectual outlook: "... but at the same time, surrealism had already permeated the (French intellectual) culture. Through exhibitions, it was present in my cultural environment. And it was marked by a coefficient of value." This coefficient of value describes "things which I would look at positively, if only because they were marked by a sign of marginality, subversion, cultural rebellion, and so on. I never felt mainstream. This was the general attractiveness or rebellious cultural movement in surrealism" (Bouissac, as quoted in Riggins 2003: 100).

Given the spontaneity surrealists idealized, it is an interesting juxtaposition to put Dali in the context of structures of control on the body and gender. But the motives behind surrealism no doubt parallel some of the practices of tattooing. Tattoos are very often a form of surrealist art in that they are marks of expression that can, and have been, tied to rebellion, cultural subversiveness, and social marginality. One aspect of getting tattooed is the topic of control, in Rachael's case the decision to hide her tattoos, if necessary: ${ }^{3}$

Well I actually started placing them in spots that made the tattoos nice but so they could also be hidden. You know, if I have to get a job or

\footnotetext{
${ }^{3}$ All (100\%) respondents indicated some form of concern for their tattoos when it came to employment. Although this is most likely a result of the fact that all respondents are students working toward a career, it is nonetheless very telling of the cultural misconceptions about tattoo enthusiasts that still exists and thus have real consequences.
} 
anything, it was a big concern for my mom on signing off on the first couple. At the end of the day, she wanted to make sure I could still get a job.

Nevertheless, a message that Rachael's tattoo embodies is that a tattoo can equally be a sign of personality and self-expression while doubling as a sign of cultural difference or rebellion. For example, Rachael's comment quoted earlier, which expresses the way she believes other people view her body as "damaged goods" shows how her tattoos are living examples of the constraining and enabling aspects of structure. The only way a tattooee can claim to be different is by first being the same. But this does not mean that the notions of surrealist art die when one chooses to adhere to certain "civilizing processes" (Atkinson 2004; Elias 2000).

Tattoos are, first and foremost, about self and social expression; and this means they can be a sign of adherence to culture while, at the same time, a mark of difference, personality, and uniqueness. As both are present, it is not intellectually sound to claim that tattoos are only an adherence to cultural repertoires of body projects suited strictly to prove the enthusiast is part of a collective. On the other hand, it is also not sound to claim that tattoos are only about being different, unique, and disconnected from the status quo. The expressive nature of tattoos becomes complicated when they bridge the relationship between individual and culture. This is why tattoos can be about being part of a figuration, but they can also be part of a deeply personal story. "Like when I look at my arms," Rachael says, "I felt they were always meant to be there - like a birthmark or something. I can't even imagine myself without them at this point.... And for me, these are for me. I'm okay with not everyone being able to always see them all the time. They are also about being fun and representing growing up a little bit."

In sum, Rachael's Salvador Dali tattoo of a rose floating in air - illogical surrealist image and a symbol of traditional femininity - is yet another example of a tattoo's "coefficient of value." Even if surrealists aim to find the unconscious logic in the illogical, and soon end up with some standardized images, there is always the possibility of creativity in art and in interpretation. And even while feminist movements have fundamentally altered the way we view gender inequalities, influences still remain from structures of control which contend with structures of change and creative individuality. The structures of control are forces like hegemonic masculinity and ideal body types that continue to fuel the fight for equality among scholars in gender studies (Atkinson 2011; Kimbrell 1995) and feminism (MacKinnon 1989; Smith 1987). 


\section{Mapping: Rachael's "T.V. on the Radio" Lyrics}

As was the case with Roger, music plays a big part in Rachael's life and functions as a social facilitator (Riggins 1994:113) for friendships and relationships. During our interview Rachael spoke repeatedly about her boyfriend, an English Major, musician, and a tattooed person. When speaking about the popularity of text tattoos, Rachael mentions how she "had (her) boyfriend look over (her) tattoo a dozen times to assure the grammar would be correct, just in case." The lyrics Rachael has tattooed on her left forearm are: "Just like autumn leaves we're in for change." The message comes from the song "Province" by the band T.V. on the Radio. The idea of change is something that this article broaches time and time again, in reference to meanings, identity, emotions, expressions, etc. This is why I believe Rachael's tattoo about change is an insightful commonsense addition to my dataset.

Rachael describes the tattoo by saying "I think about that (changing). I think if I could always like a tattoo as specific as these lyrics. But even if I change, these are the things that are important to me in different times of my life. So I will never hate them." Tattoos form part of our social and cultural repertoires as enthusiasts. But they also form part of our body, our skin, our story. Tattoos represent how even the most permanent of things like body and mind change over time even while they remain the same. Rachael describes the liberating feeling when we understand change as both inevitable and enabling: "I spent the whole summer before coming to university planning out my next four years and I have figured out you can't plan everything. Things will change and this is not a bad thing." The chorus of "Province" by T.V. on the Radio says "all our memories are precious as gold." One lesson I have learned from my discussions with these enthusiasts and from myself is that tattoos are a powerful way humans have invented for preserving what is most precious in our lives. Memories fade more quickly than the ink of tattoos. 
Figure 6.

\section{Elle}
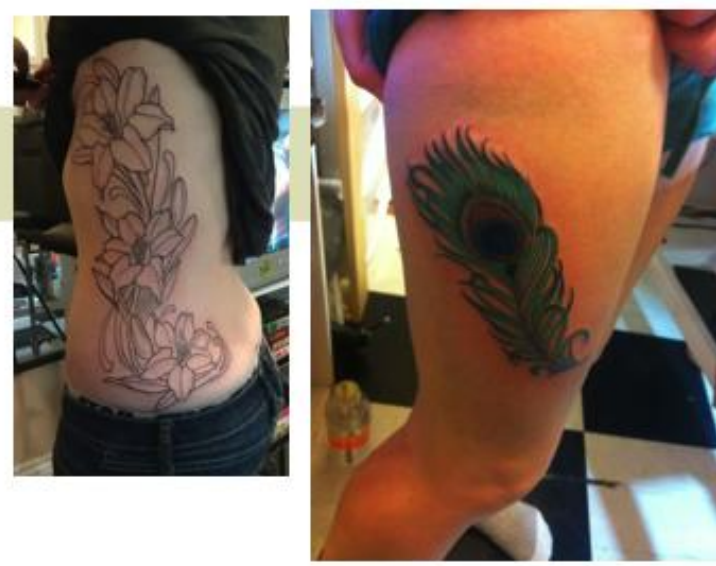

Description

Gender: female.

Location on Body: right thigh, left torso.

Colours: green, blue, burnt orange.

Design: peacock feather, three lilly on a

vine.

Text: N/A.

Visibility: can be hidden with pants and tshirt.

Style: realism, new school

Symbolic Meanings: katimavik, women's shelter volunteer, sisters and family.

Social/Cultural Aspects: feminism, masculinity crisis, feeling pretty.

\section{Elle}

\section{The Peacock Revisited}

\section{Referencing - Elle's Peacock Feather}

Elle's peacock feather tattoo was influenced by the idea that "the really pretty (peacock feathers) actually belong to the male ... and although the feather belongs to the masculine, it can also be pretty." According to Elle, "I know women have always been marginalized by gendered assumptions, but I am also interested in the masculinity crisis." Elle's feelings about her tattoo are reflective of her opinions about the issues of gender, the body, and feminism in Western culture. For Elle, her tattoos represent an act of rebellion from gender stereotypes or assumptions; but they also represent her connection with her human desire to look and feel pretty and to be part of a collective.

Although the idea of feeling pretty is often equated with femininity, this article has shown - through the use of the peacock feather - that tattoos are about demonstrating a 
favorable aspect of self and social identity to others for both men and women. Thus, what Elle's tattoo says about the gender lines of society and the current state of feminist scholarship is entangled with notions of her human desires to be attractive, to fit in, and by the masculinity crisis. Just like the motivations for her tattoo, Elle's opinions on feminism demonstrate a popular new spin on gender studies (see Atkinson 2011; Faludi 1999; Farrell 2001). This is the connection between resisting or rebelling against the hegemony and patriarchy of Western culture (or perhaps world culture), while also understanding complicated identities and human emotions which obfuscate meta-narratives of an egalitarian society. Here is what Elle says about the discipline of feminism:

Well, you get into this whole grey area. Sometimes I hate what feminism has been equated with. I recognize that my female sisters have been wholly oppressed, but I have been given so many opportunities being female. Basically, I feel I would just be a lot happier if gender didn’t exist.

Since Elle mentions the masculinity crisis and the notion of the pretty peacock, scholars writing in the field of gender and masculinity studies need to be discussed here. As I understand the topic, they allow for a new spin on scholarship which describes no gender as "safe" from the perils of mistaken and misattributed identities and confused states of belonging. The most valuable lesson of any study trying to explain gender is that a focus on the micro before attacking the macro is necessary for understanding the nuanced mistreatment of others based on gender for both men and women. In other words, although shattering glass ceilings may be on the agenda, those who live above and below should first be forewarned before their realities become shards of broken glass.

According to Atkinson (2011: 42), the principles of Bauman's Liquid Modernity (2001) and Giddens' high or late modernity (1991) can help us understand the ever-changing - interaction specific - gender performances of skilled social actors in everyday life: "The late modern man is powerful when he finally accepts and wields his ability to change the nature and performance of his masculinity when need be, when emergent situations demand him to enact gender in a variety of ways." Susan Faludi makes a similar observation of the complicated roles a man faces in contemporary culture in her influential book Stiffed: The 
Betrayal of the American Man (1999). While participating in ethnographic research at weekly-meetings of domestic violence groups, Faludi makes note of the men who had "lost their compass in the world. They had lost or were losing, jobs, homes, cars, and families. They had been labeled outlaws, but felt like castoffs. Their strongest desire was to be dutiful and to belong, to adhere with precision to the roles society has set for them as men... (and they had) nothing but the gender rule book to fall back on" (Faludi 1999: 9).

The peacock feather is a symbol for a new understanding of gender as an issue underscoring the life of men and women in the late-modern world. The tattoo is thus an act of rebellion in making note of this fact and purposefully mocking the gendered barriers of masculine/feminine, pretty/strong, male/female. But it is also representative of the confusion of roles felt by men and women in their desire to act out gender-appropriate roles in specific situations. In a sense the peacock is a confusing symbol of gender because most people will associate feathers with traditional femininity. Show girls used to wear feathers. A generation or so ago women often had feathers in their hats. Most people will overlook the fact that it is the male which has the brightest feathers in many species of birds. Elle's contribution to our understanding of the importance of structure as an enabler and constrainer is contextualized through her unwavering desire to maintain attributes of pretty and nice, while also allowing her to play on these biopolitical principles as a motivation for artwork which mocks these very principles.

Elle says, "oh yeah, I wanted to look pretty. Everyone wants to look pretty. Boys want to look pretty too." The idea of wanting to look pretty was mentioned as important to $67 \%$ of my sample and of this percentage, 2 or $20 \%$ were males. I believe this is part of the performance and communicative aspect of tattoos. As art, tattoos are designed with shapes and lines that flow, look elegant, evoke feeling, and show emotion. In this way, the artistic principles of tattoos (of which gender rules often apply) are often the ways in which tattoos can be most constrained and enabled by the structures which influence them.

\section{Mapping}

The peacock feather says a lot about very complicated socio-cultural issues. But Elle did not spend much time speaking about them. Instead, her experiences as a volunteer with Katimavik (Inuktitut for “meeting place”) are what define this tattoo's meanings for Elle. 
Katimavik is a program that began in 1977 as a mission for Canadian youth volunteers to be exposed to other cultures, people, and to a much broader appreciation of Canada as civically engaged citizens (http://www.katimavik.org/our-mission). Elle describes her participation with the program as "life-changing" and says "I was a Katimavik participant during 2008-09 and I was a volunteer at a woman's shelter in Slave Lake in the nearby First Nations reserve in Blind River. Our main responsibility as volunteers was to decorate and run the charity gala. The centerpiece for the tables was peacock feathers and as a parting gift they gave me an Inuksuk and two peacock feathers from the gala."

The influence this program had on Elle's life is very evident not only in her choice to make this symbol permanent on her body, but also in the way she describes the feelings of empowerment in helping women and coming to an understanding of what it means to be a woman and part of a team. Elle says her family does not generally support her tattoos, but "the tattoo on my leg has a lot of significance to me. So my family members seem to try and to understand a little when I tell them.”

\section{Conclusions}

Through the case studies of these six tattooees and the supporting knowledge and perspective given by the rest of my sample, this article has identified three categories of tattoo enthusiasts who embody and describe what it means to be tattooed in the modern world, and importantly what tattoos can mean to those who don them and to the culture and history of symbols which contextualize them. Every mark of self and culture that we make on the world is always influenced by a plethora of circumstances and principles. I have identified three categories of interviewees: (1). Social Peacocks, (2). Familial Hearts, (3). Beauty and Art Enthusiasts. This allows for an interpretation of Giddens' structuration theory and thus corresponds to the following ingredients in the constitution of social action:

1. Those which allow us to see an example of the creative human agency.

2. Those which are inspired by the enabling aspects of structure (family).

3. Those which demonstrate both the enabling and constraining aspects of social structure. 
In each category I have drawn out the multiple meanings existing in the ink through tools introduced by Riggins (1990, 1994), referencing and mapping. The overall message is that tattoos are more than marks of culture or marks of individuality. They are something we make in order to be in contact with other people, but also to be in contact with ourselves.

Tattoos are about self and social expression and this means for some people that they may have a rebellious feel to them. They may be about setting yourself apart. But they are never about only one thing. Because they mean something different to us than to the people around us, some may consider our ink rebellious while we consider it artistic, beautiful, signs of love, or memento of where we've been. The cliché "don't judge a book by its cover" is a relevant conclusion to this research because as we have seen through an exploration of the genres of art (surrealism, Greek myths, contemporary photography, Japanese tattooing); and through references to feminism, elite literature, and ancient theological texts, that tattoos are much more complicated than they are normally depicted.

Tattoos are symbolic of the places we have been, the people we have known and have been in conversation with, and even the intrigue we have as social beings with far-off places we have not, or may never, experience. Popular tattoo designs like Chinese characters, Latin phrases, or Japanese mythical images can be seen tattooed on bodies of individuals who are not fluent in either the language or the cultural nuances reflected in these "far-off" designs. From this research, I wish to theorize the following reason for such discrepancies: First, people get tattoos that may be in different languages or have obfuscated meanings in some way because this is part of the ability agents have in making meaning coded and controlled. We note this with Morris who wishes to have his tattoos sometimes be a secret to himself or from the occasional onlooker. Second, tattoos are about art and this means enthusiasts and their tattoo artists often work together to create designs that are both personally and visually/socially appealing. This means people choose designs often because of aesthetics, capabilities of the art of tattooing, and its relevancies to their wishes and tastes. For example, Rachael expressed these ideas while talking about the placement of her tattoos and transformative elements of surrealist art to tattoo art. Third and finally, one of the most exciting aspects of any form of art whether it be on a canvas, vinyl, string, or skin, is its mystery and its ability to foster a multiplicity of interpretations and personal and social relevancies. When I started to research this topic I found a book at a local bookstore that had connected some popular tattoo designs with a finite definition of the symbol across the page. This book gave me the motivation to do research that did the exact opposite. Readers should 
not leave this discussion with an understanding of what some tattoos mean, but instead what tattoos can mean and how this meaning will change over time and space and from person to person.

\section{References}

Ades, Dawn (1983). Dali and Surrealism. New York: Harper and Row

Adorno, Theodor and Rolf Tiedemann (Ed.) (2004). Aesthetic Theory. Trans. Robert HullotKentor. Minneapolis: University of Minnesota Press

Alger, Janet and Stephen Alger (2003). Cat Culture: The Social World Of a Cat Shelter. Philadelphia: Temple University Press

Atkinson, Michael (2003). Tattooed: The Sociogenesis of a Body Art. Toronto: University of Toronto Press.

Atkinson, Michael (2004). "Tattooing and Civilizing Processes: Body Modification as SelfControl." The Canadian Review of Sociology, May.

Atkinson, Michael (2012). Conversation with Chris Martin. Annual meeting of the

Canadian Sociological Association, Waterloo, Ontario. May 31.

Atkinson, Michael (2010). Deconstructing Men and Masculinities. Oxford: Oxford University Press.

Becker, Howard Saul (1982). Art Worlds. Berkeley: University of California Press.

Blumer, Herbert (1969). Symbolic Interactionism: Perspective and Method. New Brunswick NJ: Prentice-Hall

Bourdieu, Pierre and Robert Johnson (1993). The Field of Cultural Production: Essays on Art and Literature. New York: Columbia University Press.

Bouissac, Paul (1985). Circus and Culture: A Semiotic Approach. Second Printing, Lanham, MD: University Press of America

Davies, Stan Gebler (1975). James Joyce: The Portrait of the Artist. New York: Harper Collins.

Deal, William E. (2007). Handbook to Life in Medieval and Early Modern Japan. Oxford: Oxford University Press 
DeMello, Margo (2000). Bodies of Inscription: A Cultural History of the Modern Tattoo Community. Durham, N.C.: Duke University Press.

Durkheim, Emile (1995[1912]). The Elementary Forms of the Religious Life. Translated by Karen E. Fields. New York: Free Press.

Durkheim, Emile (1997) [1951]. Suicide: A Study in Sociology. Glencoe: The Free Press.

Elias, Norbert (1994). The Civilising Process. Oxford: Basil Blackwell.

Foucault, Michel (1972). The Archaeology of Knowledge. New York: Pantheon Books.

Foucault, Michel (1977). Discipline and Punish: The Birth of the Prison. London: A. Lane.

Foucault, Michel (1982). The History of Sexuality. New York: Vintage Books.

Friedan, Betty (1963). The Feminine Mystique. New York: W.W. Norton and Co.

Garfinkel, Harold (1964). Studies in Ethnomethodology, Cambridge: Polity Press.

Giddens, Anthony (1976). New Rules of Sociological Method: a Positive Critique of interpretative Sociologies. London : Hutchinson.

Giddens, Anthony (1979). Central problems in Social Theory: Action, Structure and Contradiction in Social Analysis. London : Macmillan.

Giddens, Anthony (1982). Sociology: A Brief but Critical Introduction. London : Macmillan.

Giddens, Anthony (1985). The Constitution of Society: Outline of the Theory of Structuration. Cambridge: Polity.

Giddens, Anthony (1991). Modernity and Self-Identity. Self and Society in the Late Modern Age. Cambridge: Polity.

Gilbert, Steve (2000). Tattoo History: A Sourcebook. San Francisco: Juno Publishing.

Goffman, Erving (1959). Presentation of Self in Everyday Life. Garden City: Doubleday. Goffman, Erving (1963). Stigma. Englewood Cliffs: Spectrum.

Goffman, Erving (1974). Frame Analysis. Cambridge. Harvard University Press.

Greenberg, Clement (1939). “Avant-Garde and Kitsch” The Partisan Review pp. 34-49

Guth, Christine. (1996) Art of Edo Period Japan: The Artist and the City 1615-1868. Princeton: Harry N. Abrams Publication.

Heritage, John (1984). Garfinkel and Ethnomethodology. Cambridge: Polity Press. 
Joyce, James (1928). The Portrait of The Artist as a Young Man. New York: The Modern Library.

Leslie, Esther (2000). Walter Benjamin: Overpowering Conformism. London: Pluto Press Mifflin, Margot (1997). Bodies of Subversion: A Secret History of Women and Tattoo. San Francisco: Juno Press

Overton, James (1988). “A Newfoundland Culture?” Journal of Canadian Studies, 23: (1 and 2).

Pitts, Victoria (2003). In the Flesh: The Cultural Politics of Body Modification. New York: Palgrave Macmillan.

Riggins, Stephen Harold (1990). "The Power of Things: The Role of Domestic Objects in the Presentation of Self.” In S. H. Riggins (Ed.) Beyond Goffman: Studies on Communication, Institution, and Social Interaction. Berlin: Mouton de Gruyter, 341-367.

Riggins, Stephen Harold (1994). "Fieldwork in the Living Room: An auto-ethnographic Essay.” In S. H. Riggins (Ed.) The Socialness of Things: Essays on the Socio-semiotics of Objects. Berlin: Mouton de Gruyter, 101-147.

Riggins, Stephen Harold (2003). The Pleasures of Time: Two men, a Life. Toronto: Insomniac Press.

Sanders, Clinton (1989). Customizing the Body: The Art and Culture of Tattooing. Philadelphia: Temple University Press.

Shilling, Chris (1993). The Body and Social Theory. London: Sage.

Sliwinski, Sharon (2011). In Isabelle Wallace and Jennie Hirsh (Eds.) Contemporary Art and Classical Myth. London: Ashgate. 197-214.

Smith, Dorothy. E. (1987). The Everyday World as Problematic: A Feminist Sociology. Toronto: University of Toronto Press.

Tucker, Kenneth H. Jr. (1998). Anthony Giddens and Modern Social Theory. London: Sage Publishers.

Zerubavel, Eviatar (1991). The Fine Line: Making Distinctions in Everyday Life. Chicago: The Free Press.

Zittoun, Tania (2006). Transitions: Development through Symbolic Resources. Charlotte, N.C.: Information Age Publishing. 